\title{
Lamellar Structure in Poly(tetraoxane) Obtained by the Radiation-Induced Polymerization in the Solid State
}

\author{
Toshio Kato, ${ }^{* 1, *}$ Yoshiaki NAKaSe, ${ }^{* 1}$ Osamu Yoda, ${ }^{* 1}$ \\ Isamu KurIYAMA, ${ }^{* 1}$ and Akira ODAJIMA ${ }^{* 2}$ \\ *1Japan Atomic Energy Research Institute, \\ Takasaki Radiation Chemistry Research Establishment, \\ Takasaki 370-12, Japan. \\ *2Department of Applied Physics, Faculty of Engineering, \\ Hokkaido University, Sapporo, Japan.
}

(Received November 18, 1975)

\begin{abstract}
In the small-angle X-ray scattering (SAXS) patterns of poly(tetraoxane), two discrete scatterings in the meridional direction are observed: one spot-like weak scattering corresponding to a long spacing of about $100 \AA$, and the other to that of about $500 \AA$.

The annealing effects on the long spacing of about $100 \AA$ and on the melting behavior of polytetraoxane have been investigated and compared with those of the melt-crystallized poly(oxymethylene) (lamellar crystal).

It is concluded that polytetraoxane obtained by the postpolymerization contains lamellar-type crystallites which exist between the fibrillar bundles of the extended chain crystallite, since the annealing effect in the $100 \AA$ spacing shows the characteristics of the lamellar crystal.
\end{abstract}

KEY WORDS Poly(tetraoxane) / 100-Å Long Spacing / Annealing Effect / Small-Angle X-Ray Scattering / Melting Behavior / Thickening / Preferential Orientation / Lamellae /

In a previous paper ${ }^{1}$ the melting behavior of the poly(tetraoxane) obtained by radiation-induced polymerization in the solid state was investigated; it was found that the profile of a broad double melting endotherm was related mainly to the polymer yield. The molecular weight of the polymer, as well as the polymer yield, was affected by the atmosphere during the postpolymerization. ${ }^{2}$ It was also suggested ${ }^{1}$ that polymer crystals with a high melting point were formed at an early stage of the polymerization, and at a later stage, polymer crystals of a slightly different kind might be produced, and thus the melting endotherm would become broad with a inseparable double peak. In the preceding paper, ${ }^{3}$ the annealing effect under nitrogen atmosphere showed clearly that the fine structure which gave an endotherm at a lower temperature on the heating curve of the as-polymerized poly-

* Present address: Faculty of Technology, Gunma University, Kiryu, Gunma. (tetraoxane) was different from the melt-crystallized sample, since the rearrangement of the polymer chains in as-polymerized poly(tetraoxane) took place by annealing even above $T_{\mathrm{s}}$, the starting temperature of the melting, while the melt-crystallized sample showed no rearrangement of the crystal, but only melted, by the annealing above $T_{\mathrm{s}}$.

The existence of the long period of $c a .100 \AA$ in poly(tetraoxane) polymerized at $100^{\circ} \mathrm{C}$ has been demonstrated by small-angle X-ray scatering (SAXS) photographs and electron micrographs ${ }^{4}$ without any detailed description. Several intensity maxima in SAXS of poly(tetraoxane) postpolymerized at above $90^{\circ} \mathrm{C}$ were observed by $\mathrm{us}^{3}{ }^{3}$ here two intensity maxima were clearly observed, corresponding to the long spacings of ca. $100 \AA$ and $c a .500 \AA$.

In this paper, the structure of the as-polymerized poly(tetraoxane,) especially the long spacing of $c a .100 \AA$, is investigated from the annealing effects on the sample, using X-ray 
scattering methods and thermal analysis.

\section{EXPERIMENTAL}

Tetraoxane crystal (ca. $1 \mathrm{~mm} \times 10 \mathrm{~mm}$ ) was prepared by sublimation under reduced pressure, and heated at $105^{\circ} \mathrm{C}$ for $1 \mathrm{hr}$ before irradiation to remove the residual strain in the monomer crystal. The preirradiated $\left(10^{5} \mathrm{R}\right.$ at $25^{\circ} \mathrm{C}$ in air) samples were postpolymerized in a solid state at $105^{\circ} \mathrm{C}$ for $6 \mathrm{hr}$ in air. Poly(tetraoxane) thus prepared, which has a polymer yield of $48 \%$, appeared to keep the same needle like shape as the monomer crystal.

Poly(oxymethylene diacetate) (acetylated poly(trioxane $)^{5}$ ) was compared with poly(tetraoxane) in annealing effect. The samples were annealed under a nitrogen atmosphere in an apparatus which was used also for the study of melting behavior. After annealing for a given time at a desired temperature, the sample was cooled to about $100^{\circ} \mathrm{C}$ at a rate of $64^{\circ} \mathrm{C} / \mathrm{min}$.

The apparatus for the $\mathrm{X}$-ray scattering was a Rigaku Denki RU-3 rotating anode $\mathrm{X}$-ray unit operated at $40 \mathrm{kV}, 80 \mathrm{~mA}$. The monochromatic $\mathrm{CuK} \alpha$ radiation was directed normal to the $c$ axis of the needle-like poly(tetraoxane) crystal. The wide-angle X-ray scattering (WAXS) patterns were obtained photographically with a flat

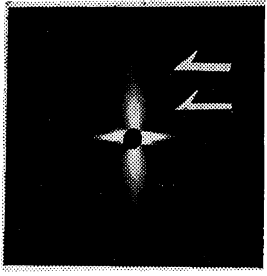

A

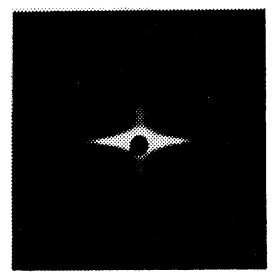

$\mathrm{E}\left(171.5^{\circ} \mathrm{C}\right)$

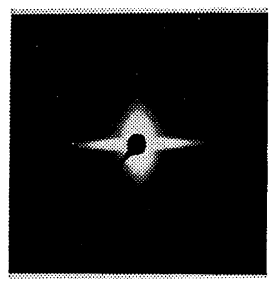

B $\left(140^{\circ} \mathrm{C}\right)$

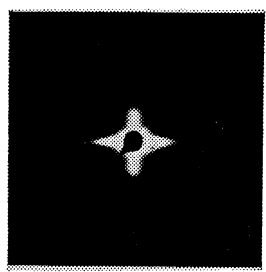

$\mathrm{F}\left(176^{\circ} \mathrm{C}\right)$

plate camera for the sample without rotation.

The small-angle X-ray scattering (SAXS) patterns were obtained also photographically with a pin-hole collimation system $(0.5 \mathrm{~mm} \phi$ and $0.3 \mathrm{~mm} \phi$ ); the specimen-to-film distance was $350 \mathrm{~mm}$. The intensity of the SAXS patterns was measured with a microdensitometer to determine the maximum position along the meridional direction.

The apparatus for the measurement of the melting behavior of polymers was a differential scanning calorimeter (DSC-1B, Perkin-Elmer) with a small amount of the sample (ca. $1 \mathrm{mg}$ ). The heating rate was $16^{\circ} \mathrm{C} / \mathrm{min}$; the instrument was calibrated with indium.

\section{RESULTS AND DISCUSSION}

Figure 1 shows the SAXS patterns of aspolymerized poly(tetraoxane) (A), the annealed $(B-G)$, and the melt-crystallized $(H)$. The annealing conditions and the results are summarized in Table I.

In SAXS of the as-polymerized (A), the diffuse equatorial scattering is observed, indicating the existence of the microvoids between fibrils. ${ }^{6}$ The two discrete scatterings in the meridional direction (indicated by half-arrows) are also observed. One is of weak spot-like

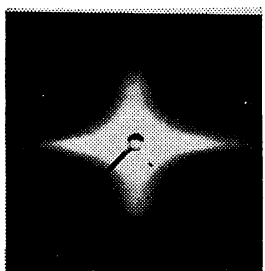

$\mathrm{C}\left(150^{\circ} \mathrm{C}\right)$

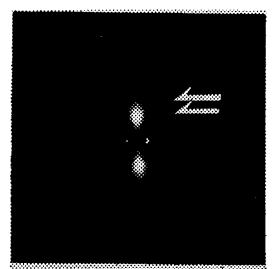

$\mathrm{G}\left(181^{\circ} \mathrm{C}\right)$

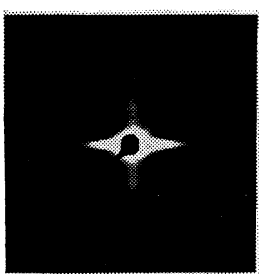

D $\left(168^{\circ} \mathrm{C}\right)$

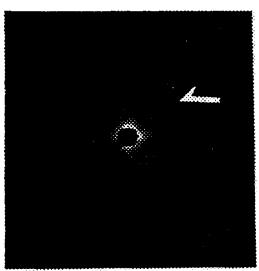

$\mathrm{H}$

Figure 1. Small-angle $\mathrm{X}$-ray scattering patterns of poly(tetraoxane) obtained by the radiation-induced postpolymerization in the solid state: A, as-polymerized; annealed $\mathrm{B}$, at $140^{\circ} \mathrm{C}$ for $30 \mathrm{~min}$; $\mathrm{C}, 150^{\circ} \mathrm{C}$, $30 \mathrm{~min} ; \mathrm{D}, 168^{\circ} \mathrm{C}, 10 \mathrm{~min}$; E, D annealed at $171.5^{\circ} \mathrm{C}$ for $15 \mathrm{~min} ; \mathrm{F}, \mathrm{E}$ annealed at $176^{\circ} \mathrm{C}$ for $12 \mathrm{~min}$; $\mathrm{G}, 181^{\circ} \mathrm{C}, 2 \mathrm{~min} ; \mathrm{H}, 195^{\circ} \mathrm{C}$ for $1 \mathrm{~min}$ (melt-crystallized); intensities are not comparable. 
Table I. The annealing conditions of poly(tetraoxane) and the results

\begin{tabular}{|c|c|c|c|c|c|c|}
\hline \multirow{3}{*}{$\begin{array}{l}\text { Sample } \\
\text { no. }\end{array}$} & \multirow{2}{*}{\multicolumn{2}{|c|}{ Annealing condition }} & \multicolumn{3}{|c|}{ Result } & \multirow{3}{*}{ Note } \\
\hline & & & \multirow{2}{*}{$\begin{array}{c}\text { Long } \\
\text { spacing } \\
l, \AA\end{array}$} & \multicolumn{2}{|c|}{ melting } & \\
\hline & ${ }^{\mathrm{T}} \mathrm{C}$ & $\begin{array}{l}\text { Time } \\
\text { min }\end{array}$ & & ${ }^{T_{\mathrm{s} 1}}$ & ${ }^{T_{\mathrm{s} 2}}$ & \\
\hline 1 & \multicolumn{2}{|c|}{-(Original) } & 95 & 171 & 179 & $A$ in Figures $1,2, \& 3$ \\
\hline 2 & 120 & 30 & 96 & 171 & 180 & \\
\hline 3 & 130 & 30 & 98 & 172 & 179 & Figure 3B \\
\hline 4 & 140 & 30 & 98 & 172 & 180 & Figure 1B \\
\hline 5 & 150 & 30 & 110 & 173 & 179 & Figure $1 \mathrm{C}$ \\
\hline 6 & 155 & 30 & 122 & 172 & 180 & Figure $3 \mathrm{C}$ \\
\hline 7 & 160 & 30 & 135 & 173 & 179 & Figure 2B \\
\hline 8 & 162 & 30 & 133 & 172 & 180 & \\
\hline 9 & 165 & 30 & 146 & 174 & 180 & \\
\hline 10 & $\begin{array}{l}(165 \\
168\end{array}$ & $\begin{array}{l}30) \& \\
10\end{array}$ & 155 & 174 & - & \\
\hline 11 & 168 & 10 & 165 & 174 & 180 & $D$ in Figures $1, \& 3$ \\
\hline 12 & $\begin{array}{l}(168 \\
171.5\end{array}$ & $\begin{array}{l}\text { 10) \& } \\
15\end{array}$ & 220 & 178 & 181 & $\mathrm{E}$ in Figures $1, \& 3$ \\
\hline 13 & 175 & 10 & $180, \& 270$ & 166 & 182 & \\
\hline 14 & $\begin{array}{l}(168 \\
(171.5 \\
176\end{array}$ & $\begin{array}{l}\text { 10) \& } \\
15) \& \\
12\end{array}$ & 240 & 180 & 183 & $F$ in Figures $1, \& 3$ \\
\hline 15 & 179 & 6 & - & 169 & 185 & \\
\hline 16 & 181 & 2 & $190, \& 280$ & 169 & 185 & $\underset{\text { Figure } 2 \mathrm{C}}{\mathrm{G} \text { in Figures } 1, \& 3, \&}$ \\
\hline 17 & $\begin{array}{l}195 \\
\text { (melt-c }\end{array}$ & $\begin{array}{c}1 \\
\text { 1lized) }\end{array}$ & 190 & 170 & - & $\underset{\text { Figure } 2 \mathrm{D}}{\mathrm{H} \text { in Figures } 1, \& 3, \&}$ \\
\hline
\end{tabular}

Figure 5 Figure 3

scattering corresponding to the Bragg spacing of about $100 \AA$ (100- $\AA$ scattering), and the other to that of about $500 \AA$ (500- $\AA$ scattering).

In the annealing at $140^{\circ} \mathrm{C}(\mathrm{B})$, the $100-\AA$ scattering remains unaltered, while the intensity maximum of the $500-\AA$ scattering shifts to the center- In the annealing above $150^{\circ} \mathrm{C}(\mathrm{C}-\mathrm{F})$, both of the maxima shift to the center, and the 500 - $\AA$ scattering goes under the beam trap. The SAXS pattern of the sample annealed at $181^{\circ} \mathrm{C}(\mathrm{G})$ is quite different from the others: namely, the equatorial scattering is very faint, indicating the diminution of the microvoids, and the weak scattering (indicated by halfarrows) equivalent to the Bragg spacing $(190 \AA)$ of the melt-crystallized (a faint ring-like scattering $(\mathrm{H})$ ) is also observed, besides the intense scattering corresponding to $280 \AA$.

Figure 2 shows WAXS patterns of the as-poly- merized poly(tetraoxane) (A), the annealed (B and $\mathrm{C}$ ), and the melt-crystallized (D). The WAXS pattern of the as-polymerized (A) shows a highly preferential orientation of the polymer chain along the $c$-axis. The WAXS pattern of the as-polymerized (A) shows no twin reflection, since the polymerization temperature of the sample (A) is $105^{\circ} \mathrm{C}$, while in the samples polymerized at below $90^{\circ} \mathrm{C}$, the twin reflection is observed clearly. Chatani, et al. ${ }^{7}$ reported that the twin reflection (the extra reflection, when compared with the usual fiber WAXS patterns, due to the twin crystal oriented perpendicular to the main crystal) was observed in the sample polymerized at $62^{\circ} \mathrm{C}$, but not in the sample at $100^{\circ} \mathrm{C}$. The present result agrees with their findings. The patterns of the annealed samples (B and C) are similar to that of the as-polymerized, though the sample annealed at 


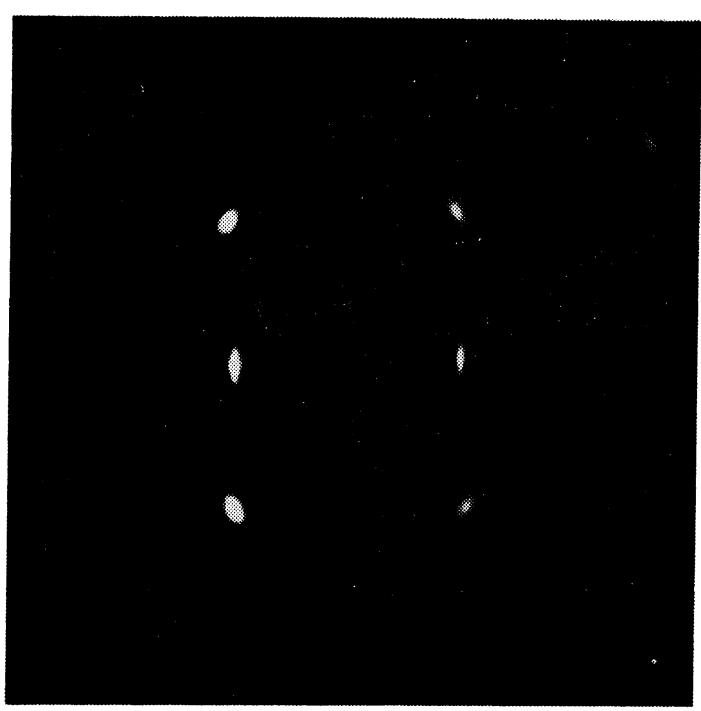

A

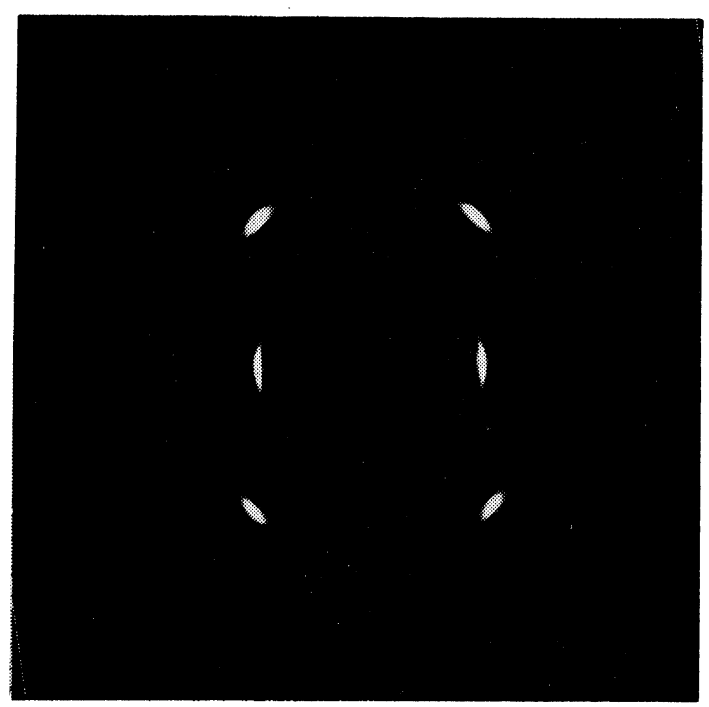

C $180^{\circ} \mathrm{C}$

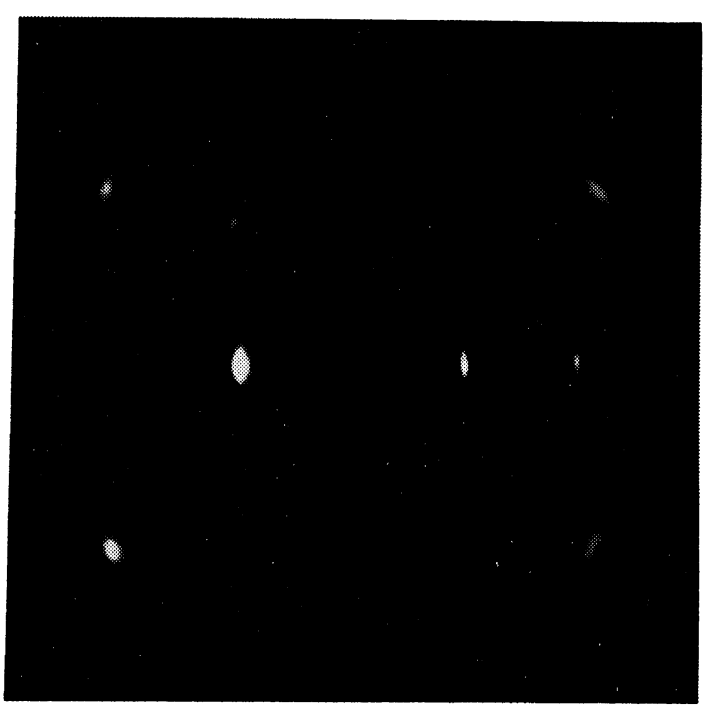

B $160^{\circ} \mathrm{C}$

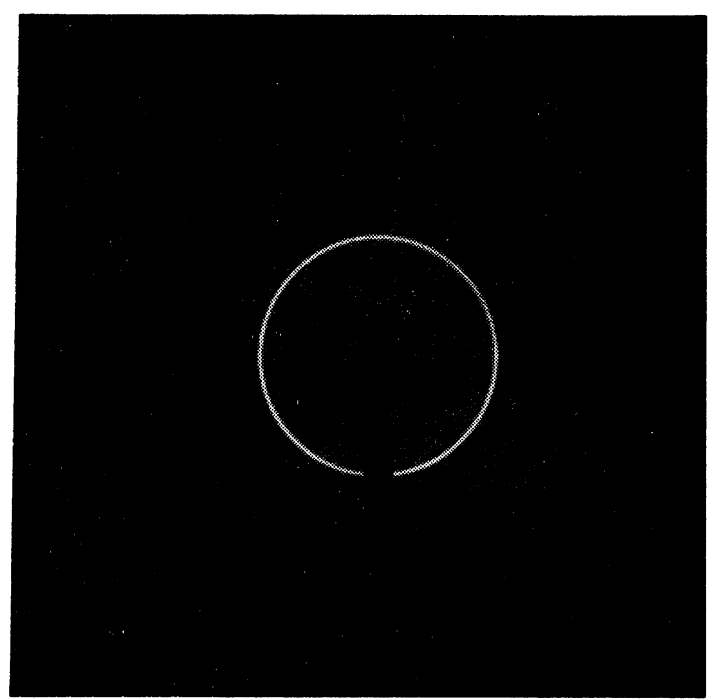

$\mathrm{D}$

Figure 2. Wide-angle X-ray scattering patterns of poly(tetraoxane): A, as-polymerized; annealed $\mathrm{B}$, at $160^{\circ} \mathrm{C}$ for $30 \mathrm{~min}$; $\mathrm{C}, 181^{\circ} \mathrm{C}, 2 \mathrm{~min} ; \mathrm{D}, 195^{\circ} \mathrm{C}$ for $1 \mathrm{~min}$ (melt-crystallized).

$181^{\circ} \mathrm{C}(\mathrm{C})$ shows the double melting endotherm in the heating curve, as described later. On the other hand, the pattern of the melt-crystallized (D) shows no preferential orientation of the polymer chains.

An amorphous halo inside the crystal reflection (100) is detected if one inspects closely the WAXS photographs of all samples.
Melting Behavior of the Annealed Samples

Figure 3 shows the heating curves of the aspolymerized poly(tetraoxane) (A), the annealed $(B-G)$, and the melt-crystallized $(\mathrm{H})$. The samples (B-D and $G$ ) are annealed directly at the desired temperature, and $\mathrm{E}$ and $\mathrm{F}$ are annealed stepwise, since, as mentioned in the preceding paper, ${ }^{3}$ the annealing at the temperature 


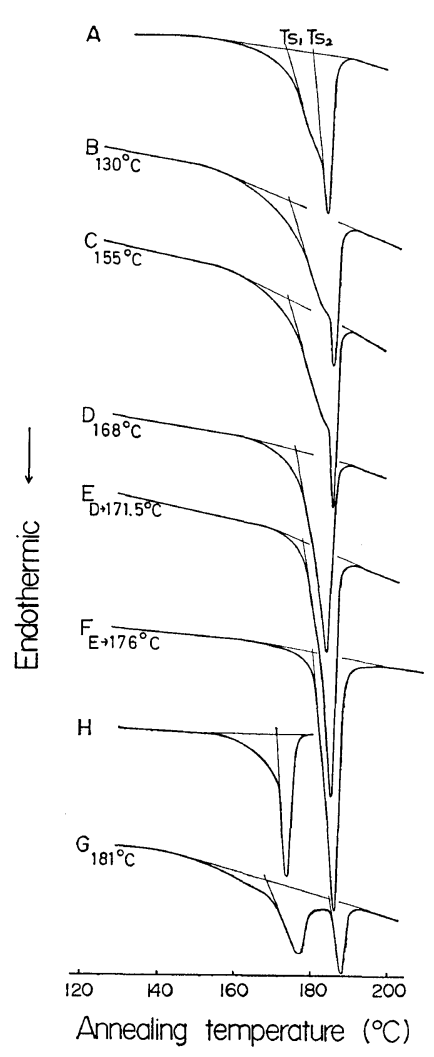

Figure 3. Heating curves of poly(tetraoxane) obtained by the radiation-induced postpolymerization (in air) in the solid state. Heating rate: $16^{\circ} \mathrm{C} / \mathrm{min}$; sample weight, $1.0 \pm 0.1 \mathrm{mg}$; A, as-polymerized; annealed $\mathrm{B}$, at $130^{\circ} \mathrm{C}$ for $30 \mathrm{~min}$; $\mathrm{C}$, $155^{\circ} \mathrm{C}, 30 \mathrm{~min} ; \mathrm{D}, 168^{\circ} \mathrm{C}, 10 \mathrm{~min} ; \mathrm{E}, \mathrm{D}$ annealed at $171.5^{\circ} \mathrm{C}$ for $15 \mathrm{~min} ; \mathrm{F}, \mathrm{E}$ annealed at $176^{\circ} \mathrm{C}$ for $12 \mathrm{~min}$; $\mathrm{G}, 181^{\circ} \mathrm{C}, 2 \mathrm{~min} ; \mathrm{H}, 195^{\circ} \mathrm{C}, 1 \mathrm{~min}$ (melt-crystallized).

below the starting temperature of the melting $\left(T_{\mathrm{s}}\right)$ of the sample causes the rearrangement of the polymer chains, while above $T_{\mathrm{s}}$ the melting occurs during annealing.

Poly(tetraoxane) shows the double melting endotherms in the heating curve, so the starting temperature of the melting endotherm at the lower temperature denotes $T_{\mathrm{s} 1}$, and that at the higher temperature $T_{\mathrm{s} 2}$, as shown in Figure 3 . $T_{\mathrm{s} 1}$ of the as-polymerized (A) is $171^{\circ} \mathrm{C}$, therefore the annealing temperature of $168^{\circ} \mathrm{C}$ is below $T_{\mathrm{s} 1}$ of the sample $\mathrm{A}$; then a sharp melting endotherm can be obtained in the heating

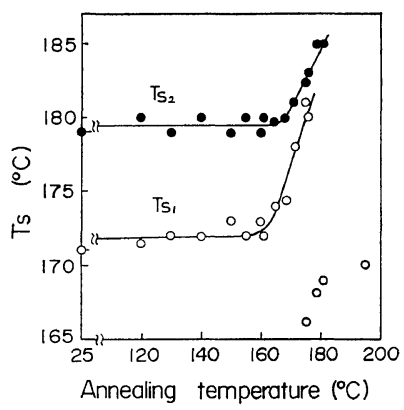

Figure 4. Effect of annealing on the starting temperature of the melting $\left(T_{\mathrm{S}}\right)$, which is calculated from melting endotherms such as are shown in Figure 3.

curve, as shown in Figure $3 \mathrm{D}$. The annealing at $171.5^{\circ} \mathrm{C}$ (above $T_{\mathrm{s} 1}$ of the sample $\mathrm{A}$, but below $T_{\mathrm{s} 1}$ of the sample $\mathrm{D}$ ), therefore, causes the rearrangement of the polymer chains to give a sharp melting endotherm (E) when the sample $\mathrm{D}$ is used as the starting material. The situation is the same in the case of the sample $F$, obtained by annealing the sample $\mathrm{E}$ at $176^{\circ} \mathrm{C}$.

The annealing of the sample $\mathrm{A}$ at the temperature $\left(181^{\circ} \mathrm{C}\right)$ above $T_{\mathrm{s} 1}$ causes the partial melting to show a double melting endotherm (G) in the heating curve. The endotherm at the lower temperature is similar to that of the melt-crystallized $(\mathbf{H})$.

The change of the melting profile in the heating curve caused by the annealing is represented by $T_{\mathrm{s} 1}$ and $T_{\mathrm{s} 2}$, as shown in Figure 4 , where the weight loss during annealing is less than $5 \%$, even at the temperature of $181^{\circ} \mathrm{C} . T_{\mathrm{s} 1}$ becomes higher in the annealing above $160^{\circ} \mathrm{C}$, while $T_{\mathrm{s} 2}$ increases above $170^{\circ} \mathrm{C}$. These changes of $T_{\mathrm{s} 1}$ and $T_{\mathrm{s} 2}$ in the annealing are quite similar to that reported in the previous paper, ${ }^{1}$ though $T_{\mathrm{s} 2}$ in this paper is higher. This difference may be attributed to the polymer preparation conditions. In the previous paper, ${ }^{1}$ poly(tetraoxane) was prepared in vacuo in the form of a powder with the polymer yield of $27 \%$, while in this paper, the needle-like crystalline sample has been obtained in air with the polymer yield of $48 \%$. The plots of $T_{\mathrm{s}}$ below $170^{\circ} \mathrm{C}$ in Figure 4 are of the crystal formed from the partial melt on cooling, and the mark at the annealing temperature $195^{\circ} \mathrm{C}$ is of the melt-crystallized sample. 


\section{Annealing Effect on the 100- $A$ Scattering}

Figure 5 shows the relationship between the annealing temeratures and the long spacings of the $100-\AA$ scattering. The long spacing of the $100-\AA$ scattering stays constant in the annealing below $140^{\circ} \mathrm{C}$, while it increases in the annealing above $150^{\circ} \mathrm{C}$, and abruptly above $165^{\circ} \mathrm{C}$. The long spacing of the melt-crystallized is about $190 \AA$.

In the samples annealed directly at $175^{\circ} \mathrm{C}$ (Table I no. 13) and $181^{\circ} \mathrm{C}$ (Table I no. 16), two intensity maxima are observed. One long spacing at a higher angle corresponds to that of the melt-crystallized mentioned above, and the other at a lower angle to the developed 100 - $\AA$ spacing. But the sample annealed below $T_{\mathrm{s}}$ of the starting material, even at $176^{\circ} \mathrm{C}$, (Table I no. 14) gives only one long spacing $(240 \AA)$ of the developed $100-\AA$ spacing.

The increase of the $100-\AA$ spacing occurs in the annealing above $150^{\circ} \mathrm{C}$, which is about $10^{\circ} \mathrm{C}$ lower than the temperature from which $T_{\mathrm{s} 1}$ increases by annealing. That is, the increase of the $100-\AA$ spacing takes place before the occurrence of the rearrangement of the polymer chains in the melting behavior, indicating a very small enthalpy change in the annealing below $160^{\circ} \mathrm{C}$. However, the fine texture with the $100-\AA$ spacing relates to the structure giving the melting endotherm at the lower temperature in the heating curve, because the increase of $T_{\mathrm{s} 1}$ corresponds to the increase of the long spacing.

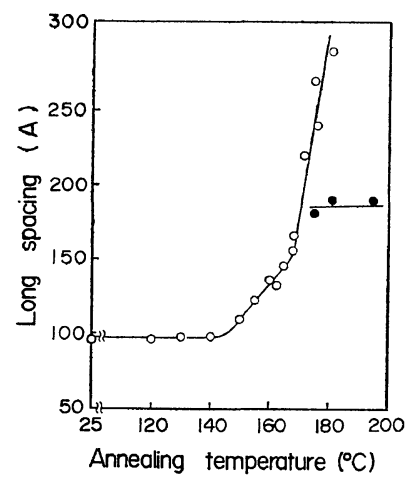

Figure 5. Relationship between annealing temperatures and long spacings of about $100 \AA$ in an original sample $(\bigcirc)$, and the melt-crystallized $(\mathbf{O})$.
Annealing Effect of the Melt-Crystallized Poly(oxymethylene diacetate)

The thickening of a lamellar crystal by the annealing was investigated in the samples of the melt-crystallized poly(oxymethylene). Figure 6 shows the SAXS patterns of the melt-crystallized poly(oxymethylene) (A) and the annealed (B-E). The faint ring-like scattering of the original sample becomes smaller in diameter in annealing, indicating the increase of the lamellar thickness. The WAXS patterns also show ringlike scatterings to indicate that there is no preferential orientation, though the figures are eliminated.

Figure 7a shows the relationship between the long spacings of the melt-crystallized samples and the annealing temperatures. The long spacing of the melt-crystallized increases with the annealing temperature above $150^{\circ} \mathrm{C}$. A similar increase of the long spacing was reported in the cases of poly(oxymethylene) ${ }^{83}$ and its copolymer ${ }^{9}$ during the annealing, and also in the case of Delrin ${ }^{8}$ with the increase of the recrystallization temperature.

The values of the long spacings in each sample differ depending on the history of the polymer preparation, and hence the onset of the long spacing increase in annealing also differs within a few degrees.

Figure $7 \mathrm{~b}$ shows that $T_{\mathrm{s}}$ of the melt-crystallized shifts to a higher temperature in the annealing above $150^{\circ} \mathrm{C}$.

Figures $7 \mathrm{a}$ and $\mathrm{b}$ show that when the long spacing increases by annealing, $T_{\mathrm{s}}$ of the annealed sample also increases. The rearrangement of the polymer chains of the melt-crystallized in the annealing causes the increase of both melting point and long spacing. In other words, the thickening of the lamellar crystal occurs if the annealing is performed at a temperature above $150^{\circ} \mathrm{C}$, but below $T_{\mathrm{s}}$ of the starting sample. ${ }^{3}$

In conclusion, it has been confirmed that the characteristics of the lamellar crystal are the increase of the long spacing and the increase of the starting temperature of the melting by annealing under the conditions mentioned above. 
Lamellar Structure in Poly(tetraoxane)

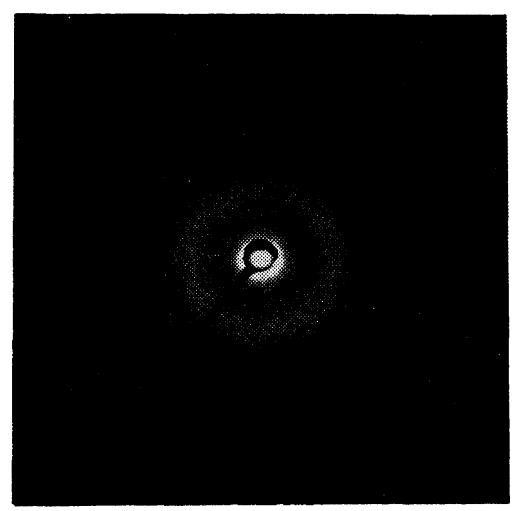

A

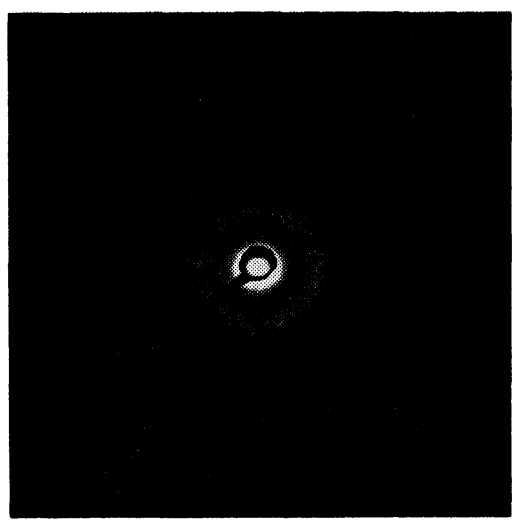

$\mathrm{C}\left(165^{\circ} \mathrm{C}\right)$

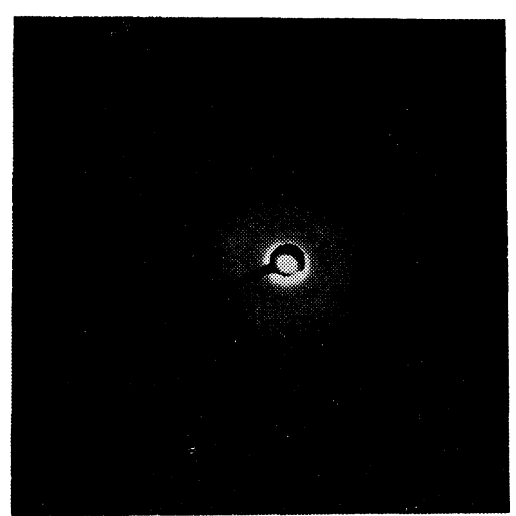

$\mathrm{E}\left(172^{\circ} \mathrm{C}\right)$

Comparison of the Annealing Effect on the 100- $\AA$ Spacing in Poly(tetraoxane) with that on the Long Spacing in the Melt-Crystallized Poly(oxymethylene)

Figure 8 shows the relative increases $\Delta l$ of the $100-\AA$ spacing of poly(tetraoxane) and that

Polymer J., Vol. 8, No. 4, 1976

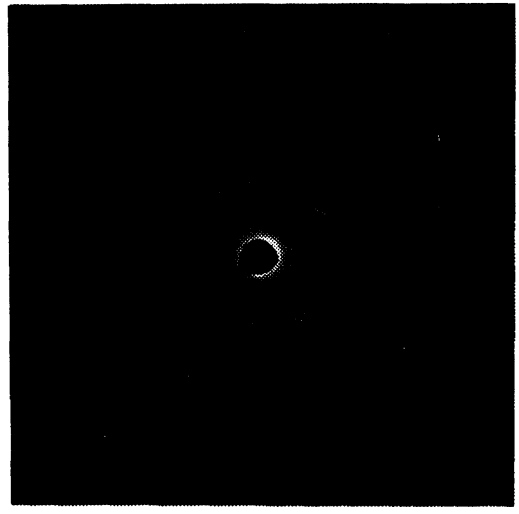

B $\left(156^{\circ} \mathrm{C}\right)$

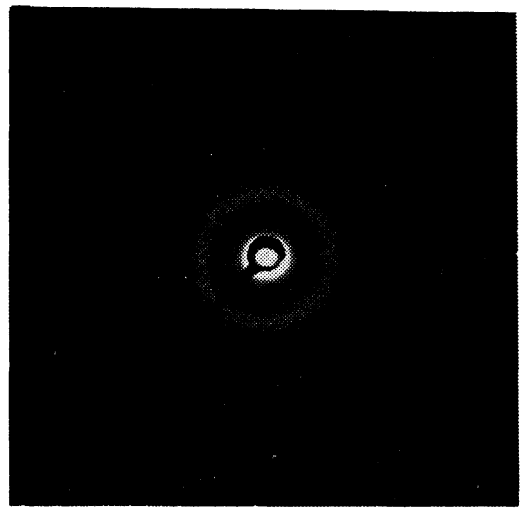

$\mathrm{D}\left(168^{\circ} \mathrm{C}\right)$

Figure 6. Small-angle X-ray scattering patterns of the melt-crystallized poly(oxymethylene), the acetylated poly(trioxane): A, melt-crystallized; annealed $\mathrm{B}$, at $156^{\circ} \mathrm{C}$ for $30 \mathrm{~min}$; $\mathrm{C}, 165^{\circ} \mathrm{C}, 20 \mathrm{~min}$; $\mathrm{D}$, $168^{\circ} \mathrm{C} 20 \mathrm{~min}$; E, D annealed at $172^{\circ} \mathrm{C}$ for $10 \mathrm{~min}$, intensities are not comparable.

of the long spacing of the melt-crystallized poly(oxymethylene), from the original values. The increments of the long spacing from the original in both samples indicate similar thickenings of lamellae in annealing above $150^{\circ} \mathrm{C}$. Similar results were reported by increasing the 


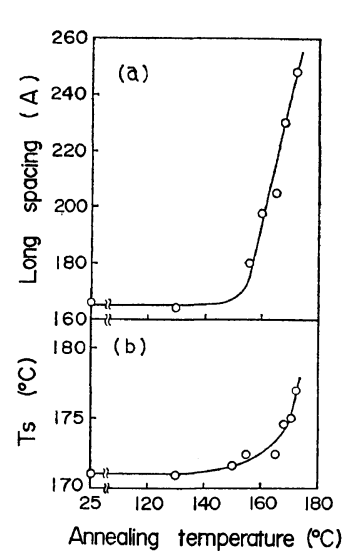

Figure 7. Relationships between annealing temperatures and long spacings of the melt-crystallized poly(oxymethylene) (a), and starting temperature of the melting $\left(T_{\mathrm{S}}\right)(\mathrm{b})$.

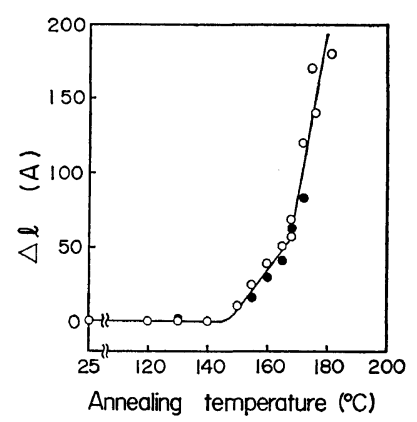

Figure 8. Relative increase of long spacing $(\Delta l)$ from the original value in the annealing, calculated from Figure $5(\bigcirc$, poly(tetraoxane)) and Figure $7($, melt-crystallized poly(oxymethylene)).

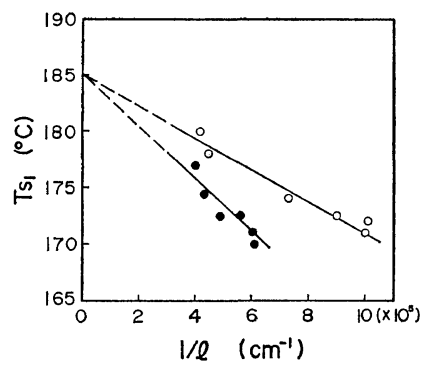

Figure 9. Relationship between starting temperature of the melting at the lower temperature $\left(T_{\mathrm{s} 1}\right)$ and the reciprocal of the long spacing: $\bigcirc$, poly(tetraoxane); $\mathbf{0}$, melt-crystallized poly(oxymethylene). recrystallization temperature for Delrin, ${ }^{8}$ and by increasing the annealing temperature for Celcon, ${ }^{9 a}$ and trioxane-dioxolane copolymer ${ }^{9 b}$ with different dioxolane contents.

Figure 9 shows the relationship between $T_{\mathrm{s} 1}$ and the reciprocal of the long spacing in both samples. The line were evaluated by the least square method. Provided $T_{\mathrm{s} 1}$ behaves as $T_{\mathrm{m}}$, it is related to the long spacing by

$$
T_{\mathrm{m}}=T_{\mathrm{m}}{ }^{\circ}\left(1-2 \sigma_{\mathrm{e}} / l \cdot \Delta H_{\mathrm{m}}\right)
$$

where $T_{\mathrm{m}}$ is the melting point of the sample, $T_{\mathrm{m}}{ }^{\circ}$ the equilibrium melting point, $l$ the long spacing, $\sigma_{\mathrm{e}}$ the end-surface free energy, and $\Delta H_{\mathrm{m}}$ the enthalpy of melting. ${ }^{10}$

The linear relation between $T_{\mathrm{s}}$ and $1 / l$ is observed as shown in Figure 9. $T_{\mathrm{p}}{ }^{\circ}$, the extrapolated peak temperature $T_{\mathrm{p}}$ of an endotherm to the sample weight $0 \mathrm{mg}$ for the melt-crystallized poly(oxymethylene), has been applied to the equation instead of $T_{\mathrm{s}}$; a quite similar result is obtained.

The similarity of the equilibrium melting temperature, $185^{\circ} \mathrm{C}$ is observed in both samples, as shown in Figure 9; this indicates a similar packing of the polymer chains between the $100-\AA$ spacings in poly(tetraoxane) and lamellae in the melt-crystallized poly(oxymethylene). The melting point must be equivalent in both samples at the extreme condition (infinite lamellar length), provided the native structure is of the same type, since the melting point $\left(T_{\mathrm{m}}\right)$ is thermodynamically defined as $T_{\mathrm{m}}=\Delta H_{\mathrm{m}} / \Delta S_{\mathrm{m}}$, where $\Delta H_{\mathrm{m}}$ and $\Delta S_{\mathrm{m}}$ are, respectively, the enthalpy and entropy of melting. The $185^{\circ} \mathrm{C}$ of the equilibrium melting temperature is not so far from the values reported for poly(oxymethylenes) in several papers. ${ }^{11}$

From these results, it is concluded that the fine texture having a long spacing of about $100-\dot{A}$ in the as-polymerized poly(tetraoxane) without the sub-crystal is of lamellar type, since it shows a quite similar annealing effect with that of the melt crystallized: i.e., the lamellar crystal.

The slope of the straight line in Figure 9 is greater in the melt-crystallized than in polytetraoxane. The slope represents the ratio of the end-surface free energy $\left(\sigma_{\mathrm{e}}\right)$ of the lamellae to the enthalpy of melting $\left(\Delta H_{\mathrm{m}}\right)$. The difference 
of the slopes suggests a difference of the lamellar stacking in the samples, that is, the lamellar crystallites in the as-polymerized poly(tetraoxane) situate between fibrillar bundles of the extented chain crystal with a preferential orientation, while those in the melt-crystallized aggregate in the form of spherulites.

Fischer, et al. ${ }^{4}$ reported that crystallization of poly(tetraoxane) at $100^{\circ} \mathrm{C}$ took place with folding using only their findings of a clear striation structure in the electron micrographs and a long spacing in a small-angle X-ray diagram.

The following data may support our suggestion: (1) The electron micrographs of poly(tetraoxane) postpolymerized in this work showed only fibrils, just like those of poly(trioxane). (2) The heating curve of the sample as-polymerized shows an inseparable double endotherm, as shown in Figure 3A, which is quite different from that of the sample annealed at $181^{\circ} \mathrm{C}$ (Figure 3G). (3) The rearrangement of the polymer chains takes place in annealing even above $T_{\mathrm{s} 1}$, as demonstrated elsewhere. ${ }^{1,3}$

\section{CONCLUSION}

The long spacing corresponding to $100 \AA$ in the poly(tetraoxane) without the sub-crystal increases in annealing at the temperatures above $150^{\circ} \mathrm{C}$, and also the starting temperature of the melting $\left(T_{\mathrm{s} 1}\right)$ increases so as to indicate the rearrangement of polymer chains during annealing. This annealing effect is a characteristic of the lamellar crystal (the melt-crystallized). Then the fine texture having a long spacing about $100 \AA$ is of the lamellar type, and this lamellar crystal gives the melting endotherm at a lower temperature in the heating curve. In other words, poly(tetraoxane) obtained by the radiationinduced polymerization in the solid state contains the lamellar crystals between fibrillar bundles of the extended chain crystals.

The details of the melting endotherm at the higher temperature and the structure with $c a$. 500- $\AA$ long spacing will be reported soon.

\section{REFERENCES}

1. Y. Nakase and I. Kuriyama, Polymer J., 4, 517 (1973).

2. Y. Nakase, M. Yoshida, A. Ito, and K. Hayashi, J. Polym. Sci., (a) Part A-1, 9, 465 (1971); (b) ibid., 10, 2181 (1973).

3. Y. Nakase, I. Kuriyama, and A. Odajima, Polymer J., 8, 35 (1976).

4. (a) T. Amano, E. W. Fischer, and Hinrichsen, J. Macromol. Sci.-Phys., B3, 209 (1969); (b) G. Wegner, E. W. Fischer, and A. MunozEscalona, Makromol. Chem., Suppl., 1521 (1975).

5. A. Ito and K. Hayashi, Hydrocarbon Processing, 47, 197 (1968).

6. W. O. Statton, J. Polym. Sci., 58, 205 (1962).

7. Y. Chatani, T. Uchida, H. Tadokoro, K. Hayashi, M. Nishii, and S. Okamura, $J$. Macromol. Sci.-Phys., B2, 567 (1968).

8. (a) D. R. Carter and E. Bear, J. Appl. Phys., 37, 4060 (1966); (b) J. J. B. P. Blais and R. St. J. Manley, J. Macromol. Sci.,-Phys., B1, 525 (1967).

9. (a) K. O'Leary and P. H. Geil, J. Macromol. Sci., B1, 147 (1967); (b) P. J. Holdsworth and E.W. Fischer, Macromol. Chem., 175, 2637 (1974).

10. J. D. Hoffman and J. J. Weeks, J. Res. NBS, 66A, 13 (1962).

11. For example, M. Jaffe and B. Wunderlich, Kolloid-Z. Z. Polym. 216/217, 203 (1967). 